\title{
Anatomia radicular de milho em solo compactado
}

\author{
Anderson Cristian Bergamin ${ }^{(1)}$, Antonio Carlos Tadeu Vitorino(1), Beatriz Lempp ${ }^{(1)}$, \\ Cristiano Márcio Alves de Souza( ${ }^{(1)}$ e Fábio Régis de Souza(1)
}

\begin{abstract}
(1)Universidade Federal da Grande Dourados, Faculdade de Ciências Agrárias, Rodovia Dourados Itahum, Km 12, Caixa Postal 533, CEP 79804-970 Dourados, MS. E-mail: andersonbergamin@hotmail.com, antoniovitorino@ufgd.edu.br, beatrizlempp@ufgd.edu.br, csouza@ufgd.edu.br, fabioagronomo@yahoo.com.br
\end{abstract}

Resumo - O objetivo deste trabalho foi avaliar a relação entre a estrutura anatômica das raízes de milho e os atributos físicos de solo submetido a diferentes graus de compactação. $\mathrm{O}$ estudo foi realizado em campo, no Município de Dourados, MS, em Latossolo Vermelho distroférrico, textura muito argilosa. O delineamento experimental foi o de blocos ao acaso, com cinco repetições. O solo utilizado apresentava histórico de oito anos com plantio direto. A compactação adicional do solo foi realizada por meio de tráfego com trator, com uma (PDc1), duas (PDc2), quatro (PDc4) e seis passadas (PDc6) sucessivas, sobre toda a área da parcela. Houve aumento na razão entre o córtex e o cilindro vascular da raiz com o aumento na compactação do solo. Essa razão correlacionou-se negativamente com a macroporosidade e positivamente com a densidade do solo e com a resistência do solo à penetração. $\mathrm{O}$ grau de compactação afeta a anatomia radicular do milho, e a resistência do solo à penetração é o indicador físico que melhor expressa esse efeito.

Termos para indexação: Zea mays, anatomia radicular, atributos físicos, densidade do solo, porosidade do solo, resistência à penetração.

\section{Anatomy of maize roots in compacted soil}

\begin{abstract}
The objective of this work was to evaluate the relationship between maize root anatomy and physical attributes of soil subjected to levels of compaction. The experiment was carried out in field conditions, in Dourados, Mato Grosso do Sul state, Brazil, in a clayed Latossolo Vermelho (Rhodic Acrustox). A randomized complete block design was used, with five replicates. The soil was cultivated for eight years under no-tillage. The additional compaction of the soil was done by tractor traffic in one (PDc1), two (PDc2), four (PDc4) and six successive passes (PDc6), in the entire area of the experimental plots. Ratio between the cortex and vascular cylinder of the root increased with soil compaction. This ratio was negatively correlated to macroporosity, and positively to soil density and soil penetration resistance. Soil compaction level affects the anatomy of maize roots, and its penetration resistance is the best physical indicator to express this effect.
\end{abstract}

Index terms: Zea mays, root anatomy, physical attributes, soil density, soil porosity, resistance to penetration.

\section{Introdução}

A utilização intensiva do solo, nos atuais sistemas de produção agrícola, tem resultado em compactação, com efeitos deletérios sobre a qualidade física do solo e sobre a produtividade das culturas (Hamza \& Anderson, 2005; Collares et al., 2006, 2008; Beutler et al., 2008). Para Hamza \& Anderson (2005), a principal causa da compactação do solo é a intensificação do uso de maquinário na agricultura. A compactação do solo eleva os valores de densidade (Ds) e resistência à penetração do solo (RP), e reduz a sua porosidade total, com efeito mais acentuado sobre a macroporosidade (Streck et al., 2004).
As consequências da compactação manifestam-se no solo e na planta. No solo, resulta no empoçamento superficial de água, erosão hídrica, poluição e assoreamento dos mananciais de água (Beutler et al., 2004). Na planta, a compactação pode impedir o crescimento de raízes e diminuir o volume de solo explorado pelo sistema radicular (Foloni et al., 2003, 2006; Beutler \& Ceturion, 2004), além de alterar a profundidade, a ramificação e a distribuição dessas raízes no solo (Cardoso et al., 2006; Collares et al., 2008).

Entre os atributos físicos do solo, a RP tem sido bastante utilizada como indicativo da compactação por apresentar relações diretas com o crescimento 
das raízes e com o tráfego de máquinas (Cardoso et al., 2006; Freddi et al., 2007; Collares et al., 2008). A RP está relacionada à umidade do solo e aumenta na medida em que o teor de água diminui (Collares et al., 2008). As pesquisas que avaliam o efeito da RP sobre o desenvolvimento das plantas, normalmente, têm sido realizadas em casa de vegetação, e podem não representar as condições de campo. $\mathrm{O}$ valor de $2 \mathrm{MPa}$ tem sido utilizado como limite crítico de RP (Beutler et al., 2004; Serafim, 2007). Em trabalho realizado em casa de vegetação, Foloni et al. (2003) observaram que o crescimento radicular do milho, em Latossolo Vermelho distroférrico de textura média, foi prejudicado em $50 \%$, quando a RP foi igual a $0,75 \mathrm{Mpa}$, e foi totalmente inibido quando ela chegou a 1,4 MPa.

Em decorrência das alterações nos atributos físicos do solo, ocasionadas pela compactação, existem relatos sobre modificações morfológicas em raízes de feijão (Collares et al., 2008); sobre adaptações fisiológicas de raízes de milho (Silva et al., 2004) e sobre alterações anatômicas em raízes de cana-de-açúcar (Queiroz-Voltan et al., 1998). Esses relatos configuram respostas de adaptação das plantas às condições adversas impostas pelo ambiente. Queiroz-Voltan et al. (2000) não verificaram diferenças no espessamento das paredes celulares dos elementos de vaso do xilema de soja, com aumento na Ds de um Latossolo Vermelho. Esses autores também verificaram que o cultivo de soja em solo com densidade máxima de $1,5 \mathrm{~kg} \mathrm{dm}^{-3}$ não alterou a razão entre o raio interno e externo ao câmbio vascular das raízes de soja. Dantas et al. (2001) e Pereira et al. (2008) observaram que raízes de milho, em condições de hipoxia, apresentavam grande parte da área do seu córtex ocupada por aerênquimas.

O objetivo deste trabalho foi avaliar a relação entre a estrutura anatômica das raízes de milho e os atributos físicos de um Latossolo Vermelho distroférrico de textura muito argilosa, submetido a diferentes graus de compactação.

\section{Material e Métodos}

O estudo foi realizado na área da Fazenda Experimental de Ciências Agrárias da Universidade Federal da Grande Dourados, no Município de Dourados, MS, no ano agrícola 2007/2008. O local situa-se na latitude de $22^{\circ} 14^{\prime} 08^{\prime \prime} \mathrm{S}$, longitude de $54^{\circ} 59^{\prime} 13^{\prime \prime} \mathrm{W}$ e altitude de 434 m. O clima é do tipo Cwa, segundo a classificação de Köppen. Os atributos físicos e químicos do solo foram determinados conforme proposto em Claessen (1997).

O solo utilizado foi um Latossolo Vermelho distroférrico, cuja composição granulométrica, determinada pelo método da pipeta, foi $644 \mathrm{~g} \mathrm{~kg}^{-1}$ de argila, $203 \mathrm{~g} \mathrm{~kg}^{-1}$ de silte e $153 \mathrm{~g} \mathrm{~kg}^{-1}$ de areia, nos primeiros $0,20 \mathrm{~m}$. As características químicas observadas foram: $\mathrm{pH}\left(\mathrm{H}_{2} \mathrm{O}\right), 5,7 ; \mathrm{Ca}^{2+}, 69,2 \mathrm{mmol}_{\mathrm{c}}$ $\mathrm{dm}^{-3} ; \mathrm{Mg}^{2+}, 31,0 \mathrm{mmol}_{\mathrm{c}} \mathrm{dm}^{-3} ; \mathrm{Al}^{3+}, 0,0 \mathrm{mmol}_{\mathrm{c}} \mathrm{dm}^{-3}$; $\mathrm{H}+\mathrm{Al}^{3+}, 58,0 \mathrm{mmol}_{\mathrm{c}} \mathrm{dm}^{-3} ; \mathrm{P}, 7,0 \mathrm{mg} \mathrm{dm}{ }^{-3} ; \mathrm{K}, 5,1 \mathrm{mmol}_{\mathrm{c}}$ $\mathrm{dm}^{-3}$ e MO, $37 \mathrm{~g} \mathrm{~kg}^{-1}$.

O delineamento experimental utilizado foi o de blocos ao acaso, com cinco tratamentos e cinco repetições. Os tratamentos foram aplicados em área que vinha sendo manejada em sistema de plantio direto por oito anos, adotando-se um sistema de rotação de culturas com soja e milho no verão, e milho safrinha e aveia-preta no outono/inverno. A compactação adicional do solo foi realizada por meio de uma (PDc1), duas (PDc2), quatro (PDc4) e seis passadas com o trator (PDc6) sobre a área de cultivo. O tratamento controle (PD) consistiu da ausência de passadas adicionais com o trator. Por ocasião da instalação do experimento, a cobertura do solo consistia de resíduo de aveia-preta. As parcelas mediram 5,0 $\mathrm{m}$ de comprimento e 3,6 $\mathrm{m}$ de largura, em uma área total de $18,00 \mathrm{~m}^{2}$, com distância entre os blocos de 8,0 m, como área para manobras das máquinas.

Os tratamentos com compactação adicional do solo foram aplicados no dia 13 de novembro de 2007, quando o solo possuía um conteúdo de água de $0,28 \mathrm{~kg} \mathrm{~kg}^{-1}$, correspondente a $90 \%$ da capacidade de campo, na camada de $0-0,20 \mathrm{~m}$ de profundidade, três dias após a ocorrência de precipitação pluvial de 147,6 mm. Foi utilizado um trator agrícola Massey Ferguson, modelo 292 $(105 \mathrm{cv})$, com rodado de pneus diagonais e massa total de $5 \mathrm{Mg}$, com pressão de inflação de $96 \mathrm{kPa}$ nos pneus dianteiros $(14,9-24 \mathrm{R} 1)$ e $110 \mathrm{kPa}$ nos pneus traseiros (18,4-34 R1), e 39\% da massa do trator era distribuída no eixo dianteiro e $61 \%$ no eixo traseiro. A compactação foi realizada por meio da passagem dos rodados desse trator, em toda a superficie da parcela, de forma que os pneus comprimissem áreas paralelas entre si. O número de vezes que o trator trafegou variou conforme o tratamento. A RP foi determinada no dia 22 de novembro de 2007, com o uso do penetrógrafo de campo, modelo SC 60 (SoilControl, São Paulo, Brasil). Os valores expressos em $\mathrm{kg} \mathrm{cm}^{-2}$ foram convertidos para $\mathrm{MPa}$ 
$\left(1 \mathrm{~kg} \mathrm{~cm}^{-2}=0,098 \mathrm{MPa}\right)$, de acordo com a norma da Asabe S313-2 (American Society of Agricultural and Biological Engineers, 2006). A amostragem foi feita à profundidade de $0-0,50 \mathrm{~m}$, em intervalos de $0,05 \mathrm{~m}$, com o uso de dez leituras para representar uma repetição. No local onde se realizaram as amostragens de resistência do solo à penetração, foram coletadas, com o uso do trado holandês, amostras de solo nas profundidades de $0-0,10$; $0,10-0,20 ; 0,20-0,40$ e $0,40-0,50 \mathrm{~m}$ para determinar a umidade gravimétrica do solo.

A semeadura do milho (cv. BRS 3150) foi efetuada no dia 22 de novembro de 2007, com uma semeadora-adubadora de plantio direto com quatro linhas. O mecanismo sulcador do solo da semeadora foi retirado para não eliminar os possíveis efeitos negativos da compactação, tendo sido utilizado somente o disco de corte do dosador de sementes. A densidade de semeadura foi de oito sementes por metro, com espaçamento entrelinhas de $0,90 \mathrm{~m}$. A adubação consistiu de 0,4 $\mathrm{Mg} \mathrm{ha}^{-1}$ da fórmula 10-30-10, para obtenção da produtividade esperada de 6 a $8 \mathrm{Mg} \mathrm{ha}^{-1}$. Decorridos dez dias da emergência das plântulas, foi realizado o desbaste para cinco plantas por metro. A adubação de cobertura foi realizada 30 dias após a emergência das plântulas, utilizando-se $0,1 \mathrm{Mg} \mathrm{ha}^{-1}$ de $\mathrm{N}$ na forma de sulfato de amônio, e $0,04 \mathrm{Mg} \mathrm{ha}^{-1}$ de $\mathrm{K}_{2} \mathrm{O}$ na forma de cloreto de potássio. Cada unidade experimental possuiu quatro linhas de milho, com cinco metros de comprimento.

Para estudar a estrutura radicular nos diferentes tratamentos, foi selecionada a camada de $0-0,05 \mathrm{~m}$ de profundidade, em razão dos maiores valores de RP encontrados nesta camada. As determinações da anatomia radicular foram realizadas quando as plantas de milho estavam no estádio fenológico R1 (florescimento e polinização). Em cada parcela foi aberta uma trincheira de $0,9 \times 0,05 \mathrm{~m}$, onde foram coletadas amostras de raízes a partir de três plantas escolhidas aleatoriamente.

As raízes foram lavadas para separação da massa de solo e, em seguida, cortadas em fragmentos de $5 \mathrm{~mm}$, fixados em formalina-acetato-álcool etílico a $50 \%$ (F.A.A. 50\%), e armazenadas em geladeira até o início do processo de desidratação. A desidratação foi realizada em série alcoólica, e os fragmentos de raízes foram embebidos em parafina e, posteriormente, em paraplast. Foram feitos cortes transversais de $12 \mu \mathrm{m}$ de espessura, em micrótomo rotativo, que foram corados com safranina orange G-fast green
FCF (Hagquist, 1974). Depois de serem montadas as lâminas permanentes, as imagens foram obtidas com um microscópio de ocular micrométrica, e, em seguida, foram realizadas as medidas da espessura do córtex e do cilindro vascular. A espessura do cilindro vascular foi determinada até o centro da medula. Foram feitas 4 medidas por planta, o que totalizou 12 medidas por parcela. Assim, foi estimada a razão entre o córtex e o cilindro vascular. Com essa razão, raízes em várias fases de desenvolvimento puderam ser comparadas.

Nas determinações da macroporosidade e da Ds, foram coletadas amostras com estrutura preservada, em cilindros metálicos com $5,57 \mathrm{~cm}$ de diâmetro e 4,10 cm de altura, na mesma profundidade e no mesmo dia em que se realizou a coleta de raízes. As amostras foram retiradas nas entrelinhas da cultura do milho. Em cada parcela, foram coletadas três subamostras, tendo sido utilizado o valor médio como representativo.

As amostras foram saturadas por meio da elevação gradual de uma lâmina de água até atingir cerca de $2 / 3$ da altura do anel. Após a saturação ter sido estabelecida, foi realizado o procedimento para obtenção da macroporosidade pelo método da mesa de tensão. Posteriormente, as amostras foram levadas à estufa a $105-110^{\circ} \mathrm{C}$ por 48 horas, para determinar a Ds pelo método do anel volumétrico.

Os resultados foram submetidos à análise de variância e ao teste de Duncan, a 5\% de probabilidade. Também foram realizadas as correlações lineares simples para as combinações duas a duas, dos atributos físicos do solo, com a razão entre o córtex e o cilindro vascular das raízes de milho.

\section{Resultados e Discussão}

O tráfego de trator alterou os atributos físicos do solo (Tabelas 1 e 2), o que evidencia que, em plantio direto, o tráfego de máquinas aumenta a Ds e a RP, e reduz a macroporosidade do solo. Resultados semelhantes foram obtidos por Secco et al. (2004), Collares et al. (2006) e Freddi et al. (2007).

Os valores de RP, nas profundidades $0-0,05$ e 0,05-0,10 m, aumentaram com o tráfego do trator (Tabela 1). Os maiores valores de RP e as maiores variações entre os tratamentos foram observados na profundidade de $0-0,05 \mathrm{~m}$. Resultados semelhantes foram obtidos por Streck et al. (2004), em Argissolo 
Tabela 1. Resistência do solo à penetração e umidade gravimétrica em diferentes profundidades, de acordo com o grau de compactação adicional aplicado ao solo pelo tráfego ${ }^{(1)}$.

\begin{tabular}{|c|c|c|c|c|c|c|}
\hline \multirow[t]{2}{*}{ Profundidade (m) } & \multicolumn{5}{|c|}{ Tratamento $^{(2)}$} & \multirow[t]{2}{*}{$\mathrm{CV}(\%)$} \\
\hline & $\mathrm{PD}$ & PDc1 & PDc2 & PDc4 & PDc6 & \\
\hline \multicolumn{7}{|c|}{ Resistência do solo à penetração (MPa) } \\
\hline $0-0,05$ & $1,06 \mathrm{c}$ & $1,13 \mathrm{c}$ & $1,26 b$ & $1,41 \mathrm{a}$ & $1,43 a$ & 5,46 \\
\hline $0,05-0,10$ & $1,03 b$ & $1,05 b$ & $1,11 b$ & $1,27 \mathrm{a}$ & $1,27 \mathrm{a}$ & 6,60 \\
\hline $0,10-0,15$ & $1,02 \mathrm{a}$ & $1,04 \mathrm{a}$ & $1,10 \mathrm{a}$ & $1,11 \mathrm{a}$ & $1,11 \mathrm{a}$ & 11,19 \\
\hline $0,15-0,20$ & $0,95 \mathrm{a}$ & $0,97 \mathrm{a}$ & $0,99 a$ & $0,99 a$ & $1,00 \mathrm{a}$ & 17,68 \\
\hline $0,20-0,25$ & $0,85 \mathrm{a}$ & $0,84 a$ & $0,85 \mathrm{a}$ & $0,86 \mathrm{a}$ & $0,86 \mathrm{a}$ & 17,89 \\
\hline $0,25-0,30$ & $0,75 \mathrm{a}$ & $0,75 \mathrm{a}$ & $0,79 \mathrm{a}$ & $0,81 \mathrm{a}$ & $0,81 \mathrm{a}$ & 19,15 \\
\hline $0,30-0,35$ & $0,68 \mathrm{a}$ & $0,70 \mathrm{a}$ & $0,73 \mathrm{a}$ & $0,74 \mathrm{a}$ & $0,74 a$ & 19,61 \\
\hline $0,35-0,40$ & $0,66 \mathrm{a}$ & $0,66 \mathrm{a}$ & $0,68 \mathrm{a}$ & $0,69 \mathrm{a}$ & $0,69 a$ & 21,85 \\
\hline $0,40-0,45$ & $0,65 \mathrm{a}$ & $0,65 \mathrm{a}$ & $0,66 \mathrm{a}$ & $0,66 \mathrm{a}$ & $0,68 \mathrm{a}$ & 24,07 \\
\hline $0,45-0,50$ & $0,64 \mathrm{a}$ & $0,66 \mathrm{a}$ & $0,67 \mathrm{a}$ & $0,67 \mathrm{a}$ & $0,68 \mathrm{a}$ & 21,04 \\
\hline \multicolumn{7}{|c|}{ Umidade gravimétrica $\left(\mathrm{g} \mathrm{g}^{-1}\right)$} \\
\hline $0-0,10$ & 0,29 & 0,29 & 0,29 & 0,29 & 0,29 & $-(3)$ \\
\hline $0,10-0,20$ & 0,32 & 0,31 & 0,30 & 0,31 & 0,32 & - \\
\hline $0,20-0,40$ & 0,36 & 0,33 & 0,34 & 0,35 & 0,35 & - \\
\hline $0,40-0,50$ & 0,36 & 0,34 & 0,35 & 0,36 & 0,35 & - \\
\hline
\end{tabular}

${ }^{(1)}$ Médias seguidas de letras iguais na linha não diferem entre si pelo teste de Duncan, a 5\% de probabilidade. (2)PD, plantio direto sem compactação adicional; PDc1, PDc2, PDc4 e PDc6, plantio direto com compactação adicional por tráfego de trator de $5 \mathrm{Mg}$ em uma, duas, quatro e seis passadas consecutivas, respectivamente. ${ }^{(3)}$ Não determinado.

Tabela 2. Valores médios de densidade do solo $\left(\mathrm{Mg} \mathrm{m}^{-3}\right)$, macroporosidade $\left(\mathrm{m}^{3} \mathrm{~m}^{-3}\right)$ e razão entre a espessura do córtex e do cilindro vascular $(\mathrm{CO} / \mathrm{CV})$ de raízes de milho de acordo com o grau de compactação adicional aplicado ao solo pelo tráfego, na profundidade de $0-0,05 \mathrm{~m}^{(1)}$.

\begin{tabular}{lccc}
\hline Tratamento $^{(2)}$ & Densidade do solo & Macroporosidade & $\mathrm{CO} / \mathrm{CV}$ \\
\hline PD & $1,12 \mathrm{~b}$ & $0,23 \mathrm{a}$ & $0,96 \mathrm{~d}$ \\
PDc1 & $1,13 \mathrm{~b}$ & $0,23 \mathrm{a}$ & $1,06 \mathrm{c}$ \\
PDc2 & $1,21 \mathrm{a}$ & $0,19 \mathrm{~b}$ & $1,58 \mathrm{~b}$ \\
PDc4 & $1,22 \mathrm{a}$ & $0,17 \mathrm{~b}$ & $1,86 \mathrm{a}$ \\
PDc6 & $1,23 \mathrm{a}$ & $0,17 \mathrm{~b}$ & $1,86 \mathrm{a}$ \\
\hline CV\% & 3,61 & 9,18 & 3,52 \\
\hline
\end{tabular}

${ }^{(1)}$ Médias seguidas de letras iguais na coluna não diferem entre si pelo teste de Duncan, a $5 \%$ de probabilidade. ${ }^{(2)} \mathrm{PD}$, plantio direto sem compactação adicional; PDc1, PDc2, PDc4 e PDc6, plantio direto com compactação adicional por tráfego de trator de $5 \mathrm{Mg}$ em uma, duas, quatro e seis passadas, respectivamente.

Vermelho-Amarelo, que verificaram aumento na RP com o tráfego.

A Ds aumentou significativamente a partir do tratamento com duas passadas do trator (PDc2) (Tabela 2). A Ds com uma passada do trator não diferiu da observada sem passadas adicionais. Estes resultados estão de acordo com Streck et al. (2004), que observaram aumento na Ds somente após a compactação adicional com quatro passadas de máquina com $10 \mathrm{Mg}$. Freddi et al. (2007), em Latossolo Vermelho distrófico de textura média, também observaram aumento na Ds pelo tráfego de tratores de $4 \mathrm{Mg}$.

Nos tratamentos PD e PDc1 foram observados os maiores valores de macroporosidade do solo (Tabela 2). Os tratamentos PDc2, PDc4 e PDc6 foram os que apresentaram os menores valores de macroporosidade, o que está de acordo com o aumento observado na Ds nesses tratamentos. Quando se compara o tratamento PD com o PDc6, verifica-se uma redução na macroporosidade de $26 \%$. Freddi et al. (2007), ao analisar a camada de $0-0,10 \mathrm{~m}$ de profundidade de um Latossolo Vermelho distrófico de textura média, submetido a compactação induzida por trator de $11 \mathrm{Mg}$, verificaram que a macroporosidade foi reduzida em $80 \%$ no tratamento com seis passadas, em comparação com o não trafegado. A menor redução na macroporosidade observada no presente trabalho pode estar associada ao menor peso do trator $(5 \mathrm{Mg})$ ou a uma melhor estruturação do solo, proporcionada pela textura mais argilosa.

Os valores de Ds e RP não foram altos e, consequentemente, os valores de macroporosidade foram superiores a $0,10 \mathrm{~m}^{3} \mathrm{~m}^{-3}$, acima do limite crítico ao desenvolvimento das plantas relatado por Pagliai et al. (2003). Feng et al. (2002) relatam que o valor de $0,10 \mathrm{~m}^{3} \mathrm{~m}^{-3}$ já causa inibição ao suprimento adequado de oxigênio às raízes, em solos argilosos. 
Foi observado aumento na razão entre o córtex (CO) e o cilindro vascular $(\mathrm{CV})$ das raízes de milho com o aumento do tráfego de trator (Tabela 2). Os tratamentos PDc4 e PDc6, que não diferiram entre si, apresentaram os maiores valores de $\mathrm{CO} / \mathrm{CV}$. Por sua vez, o menor valor foi observado no PD, que diferiu significativamente dos demais tratamentos.

$\mathrm{O}$ aumento da razão $\mathrm{CO} / \mathrm{CV}$ com a intensificação da compactação do solo tanto pode ter ocorrido pelo aumento na espessura do córtex como por uma redução na espessura do cilindro vascular (Figura 1). Neste trabalho, não se pode afirmar qual dessas estruturas de raiz foi alterada, pois as raízes não foram obtidas na mesma posição em relação ao ápice da planta, o que resultou em diferenças no estádio de desenvolvimento. No entanto, trabalhos realizados por Ferrer et al. (2004) e Pereira et al. (2008) têm mostrado que o córtex é uma das estruturas anatômicas da raiz mais sensíveis às mudanças no ambiente, enquanto o cilindro vascular praticamente não sofre mudanças. Esses autores analisaram as características anatômicas de raízes de milho em ambientes alagados e observaram que a espessura do córtex das raízes aumenta quando comparada ao cultivo que recebeu irrigação normal, enquanto a espessura do cilindro vascular não se altera. Para Queiroz-Voltan et al. (1998), áreas com Ds mais elevada estimulam o aumento na espessura do córtex de raízes de cana-de-açúcar e melhoram a aeração.

Ferrer et al. (2004) e Pereira et al. (2008) descreveram características anatômicas de raízes de milho semelhantes às encontradas neste trabalho. Abaixo da exoderme, em direção ao cilindro vascular, há a zona cortical ou córtex, constituída por células parenquimatosas que, com amadurecimento da raiz, se degeneram e formam grandes espaços intercelulares denominados aerênquima (Figura 2). O cilindro vascular é revestido pelo periciclo, que possui uma camada de células contínua e lignificada. No interior desse cilindro, encontram-se os feixes de xilema e de floema, e nas raízes bem desenvolvidas, observase a medula na zona central da estrutura. No sistema vascular, ficam evidentes as células do protoxilema e protofloema mais na extremidade do cilindro, e as células do metaxilema e metafloema na zona mais interna.

A razão $\mathrm{CO} / \mathrm{CV}$ das raízes de milho correlacionou-se de modo significativo $(p<0,01)$ e negativo com a macroporosidade $(\mathrm{r}=-0,83)$ e positivo com a Ds $(r=0,73)$ e a RP $(r=0,93)$. Pode-se observar a importância da RP sobre o desenvolvimento do sistema radicular do milho, em comparação aos demais atributos físicos do solo estudados. Como as raízes de milho crescem pelos macroporos, elas também foram significativamente afetadas por esse atributo físico do solo, o que corrobora os resultados obtidos por Abreu et al. (2004) e Servadio et al. (2005). Queiroz-Voltan et al. (1998) observaram que a razão CO/CV de raízes de cana-de-açúcar tende a ser menor em áreas menos compactadas, o que também está de acordo com o observado neste trabalho. Contudo, Queiroz-Voltan et al. (2000), ao analisar a razão entre o raio externo

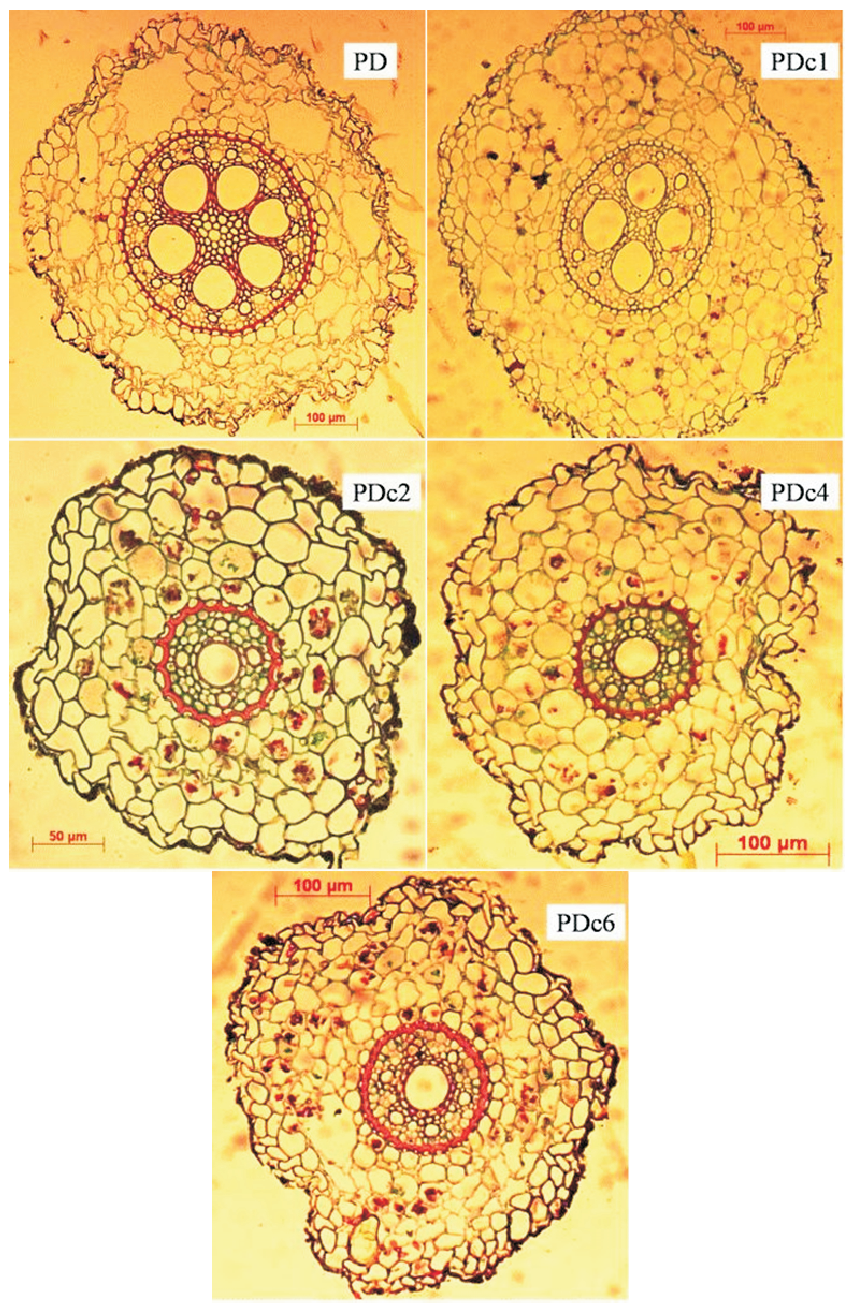

Figura 1. Cortes transversais de raízes secundárias de milho provenientes dos tratamentos plantio direto sem compactação adicional (PD), plantio direto com compactação adicional por tráfego de trator de $5 \mathrm{Mg}$ em uma (PDc1), duas (PDc2), quatro (PDc4) e seis passadas (PDc6). 


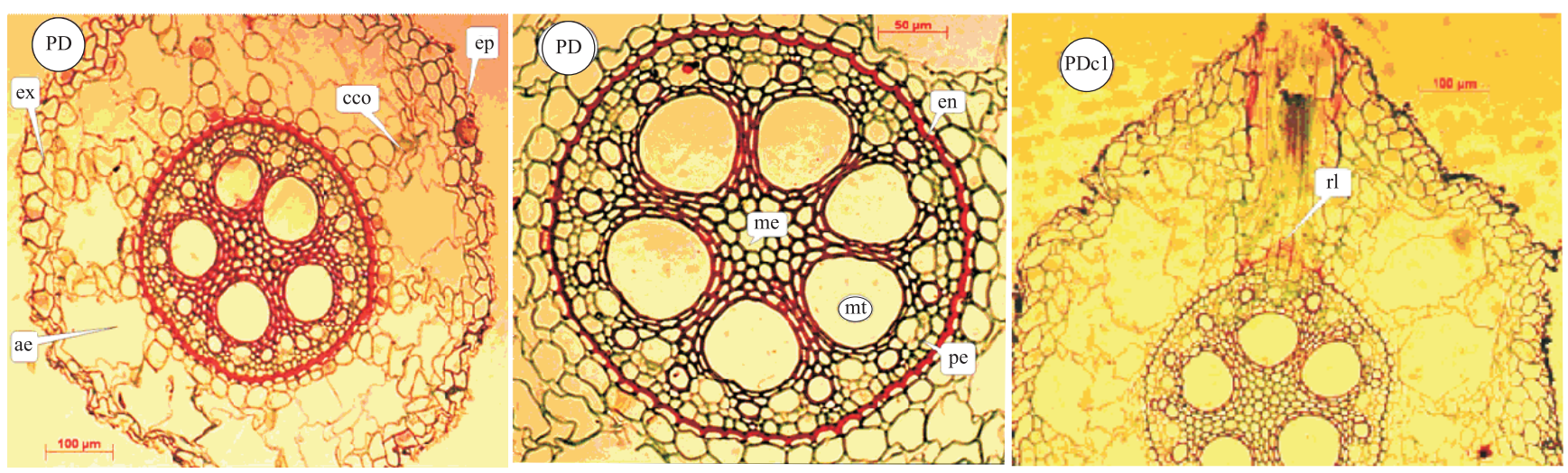

Figura 2. Anatomia radicular detalhada de raízes secundárias maduras de milho, provenientes dos tratamentos plantio direto sem compactação adicional (PD) e plantio direto com compactação adicional por tráfico de trator de $5 \mathrm{Mg}$ em uma passada (PDc1). Ep, epiderme; ex, exoderme; ae, aerênquima; cco, células do córtex; en, endoderme; pe, periciclo; mt, metaxilema; me, medula e rl, raiz lateral.

e o raio interno ao câmbio vascular de raízes de soja, não verificaram efeito significativo do aumento da densidade do solo sobre a espessura da raiz.

\section{Conclusões}

1. O grau de compactação afeta a anatomia radicular do milho, e a resistência do solo à penetração é o indicador físico que melhor expressa esse efeito.

2. A razão entre o córtex e o cilindro vascular de raízes de milho correlaciona-se negativamente com a macroporosidade e positivamente com a densidade e resistência do solo à penetração.

\section{Agradecimentos}

À Coordenação de Aperfeiçoamento de Pessoal de Nível Superior, pela concessão de bolsa de estudo ao primeiro autor.

\section{Referências}

ABREU, S.L.; REICHERT, J.M.; REINERT, D.J. Escarificação mecânica e biológica para redução da compactação em Argissolo franco-arenoso sob plantio direto. Revista Brasileira de Ciência do Solo, v.28, p.519-531, 2004.

AMERICAN SOCIETY OF AGRICULTURAL AND BIOLOGICAL ENGINEERS. ASABE standard S313.2: soil cone penetrometer. St. Joseph: ASABE, 2006. p.903-904.

BEUTLER, A.N.; CENTURION, J.F. Compactação do solo no desenvolvimento radicular e na produtividade da soja. Pesquisa Agropecuária Brasileira, v.39, p.581-588, 2004.
BEUTLER, A.N.; CENTURION, J.F.; SILVA, A.P. da; CENTURION, M.A.P.C. Soil compaction by machine traffic and least limiting water range related to soybean yield. Pesquisa Agropecuária Brasileira, v.43, p.1591-1600, 2008.

BEUTLER, A.N.; CENTURION, J.F.; SILVA, A.P. da; ROQUE, C.G.; FERRAZ, M.V. Compactação do solo e intervalo hídrico ótimo na produtividade de arroz de sequeiro. Pesquisa Agropecuária Brasileira, v.39, p.575-580, 2004.

CARDOSO, E.G.; ZOTARELLI, L.; PICCININ, J.L.; TORRES, E.; SARAIVA, O.F.; GUIMARÃES, M. de F. Sistema radicular da soja em função da compactação do solo no sistema plantio direto. Pesquisa Agropecuária Brasileira, v.41, p.493-501, 2006.

CLAESSEN, M.E.C. (Org.). Manual de métodos de análise de solo. 2.ed. rev. atual. Rio de Janeiro: Embrapa-CNPS, 1997. 212p. (Embrapa-CNPS. Documentos, 1).

COLLARES, G.L.; REINERT, D.J.; REICHERT, J.M.; KAISER, D.R. Compactação de um Latossolo induzida pelo tráfego de máquinas e sua relação com o crescimento e produtividade de feijão e trigo. Revista Brasileira de Ciência do Solo, v.32, p.933-942, 2008.

COLLARES, G.L.; REINERT, D.J.; REICHERT, J.M.; KAISER, D.R. Qualidade física do solo na produtividade da cultura do feijoeiro num Argissolo. Pesquisa Agropecuária Brasileira, v.41, p.1663-1674, 2006.

DANTAS, B.F.; ARAGÃO, C.A.; ALVES, J.D. Cálcio e o desenvolvimento de aerênquimas e atividade de celulase em plântulas de milho submetidas a hipoxia. Scientia Agricola, v.58, p.251-257, 2001.

FENG, G.; WU, L.; LETEY, J. Evaluating aeration criteria by simultaneous measurement of oxygen diffusion rate and soil-water regime. Soil Science, v.167, p.495-503, 2002.

FERRER, J.L.R.; CASTRO, E.M. de;ALVES, J.D.;ALEANCAR, M.A.; SILVA, S. da; VIEIRA, C.V.; MAGALHÃES, P.C. Efeito do cálcio sobre as características anatômicas de raízes de milho 
(Zea mays L.) "Saracura" BRS-4154 submetido ao alagamento em casa de vegetação. Revista Brasileira de Milho e Sorgo, v.3, p.172-181, 2004.

FOLONI, J.S.S.; CALONEGO, J.C.; LIMA, S.L. de. Efeito da compactação do solo no desenvolvimento aéreo e radicular de cultivares de milho. Pesquisa Agropecuária Brasileira, v.38, p.947-953, 2003.

FOLONI, J.S.S.; LIMA, S.L. de; BÜLL, T. Crescimento aéreo e radicular da soja e de plantas de cobertura em camadas compactadas de solo. Revista Brasileira de Ciência do Solo, v.30, p.49-57, 2006.

FREDDI, O. da S.; CENTURION, J.F.; BEUTLER, A.N.; ARATANI, R.G.; LEONEL, C.L. Compactação do solo no crescimento radicular e produtividade da cultura do milho. Revista Brasileira de Ciência do Solo, v.31, p.627-636, 2007.

HAGQUIST, C.W. Preparation and care of microscope slides. American Biology Teacher, v.36, p.414-417, 1974.

HAMZA, M.A.; ANDERSON, W.K. Soil compaction in cropping systems: a review of the nature, causes and possible solutions. Soil and Tillage Research, v.82, p.121-145, 2005.

PAGLIAI, M.; MARSILI, A.; SERVADIO, P.; VIGNOZZI, N.; PELLEGRINI, S. Changes in some physical properties of a clay soil in central italy following the passage of rubber tracked and wheeled tractors of medium power. Soil and Tillage Research, v.73, p.119-129, 2003.

PEREIRA, F.J.; CASTRO, E.M. de; SOUZA, T.C. de; MAGALHÃES, P.C. Evolução da anatomia radicular do milho 'Saracura' em ciclos de seleção sucessivos. Pesquisa Agropecuária Brasileira, v.43, p.1649-1656, 2008.
QUEIROZ-VOLTAN, R.B.; NOGUEIRA, S. dos S.S.; MIRANDA, M.A.C. de. Aspectos da estrutura da raiz e do desenvolvimento de plantas de soja em solos compactados. Pesquisa Agropecuária Brasileira, v.35, p.929-938, 2000.

QUEIROZ-VOLTAN, R.B.; PRADO, H. do; MORETTI, F.C. Aspectos estruturais de raízes de cana-de-açúcar sob o efeito da compactação do solo. Bragantia, v.57, p.49-55, 1998.

SECCO, D.; REINERT, D.J.; REICHERT, J.M.; ROS, C.O. da. Produtividade de soja e propriedades físicas de um Latossolo submetido a sistemas de manejo e compactação. Revista Brasileira de Ciência do Solo, v.28, p.797-804, 2004.

SERAFIM, M.E. Desenvolvimento de um penetrógrafo de bancada visando a determinação do intervalo hídrico ótimo (IHO) em diferentes sistemas de produção. 2007. 79p. Dissertação (Mestrado) - Universidade Federal da Grande Dourados, Dourados.

SERVADIO, P.; MARSILI, A.; VIGNOZZI, N.; PELLEGRINI, S.; PAGLIAI, M. Effects on some soil qualities in central Italy following the passage of four wheel drive tractor fitted with single and dual tires. Soil and Tillage Research, v.84, p.87-100, 2005.

SILVA, A.P. da; IMHOFF, S.; KAY, B. Plant response to mechanical resistance and air-filled porosity of soils under conventional and no-tillage system. Scientia Agricola, v.61, p.451-456, 2004.

STRECK, C.A.; REINERT, D.J.; REICHERT, J.M.; KAISER, D.R. Modificações em propriedades físicas com a compactação do solo causada pelo tráfego induzido de um trator em plantio direto. Ciência Rural, v.34, p.755-760, 2004.

$\overline{\text { Recebido em } 18 \text { de janeiro de } 2010 \text { e aprovado em } 19 \text { de fevereiro de } 2010}$ 